\title{
Bayramiç-Çan Arası Farklı Jeolojik ve Jeomorfolojik Araziler Üzerinde Oluşmuş Toprakların Özellikleri ve Sınıflandırılması
}

\author{
Fatma Funda Başarlar ${ }^{1 *}$ Hüseyin Ekinci ${ }^{2}$ \\ ${ }^{1}$ Mıhlı Mah. Yunus Emre Cad. Başarlar Sok. No:3 Küçükkuyu/Çanakkale \\ ${ }^{2}$ Çanakkale Onsekiz Mart Üniversitesi, Ziraat Fakültesi, Toprak Bilimi ve Bitki Besleme Bölümü, Merkez - Çanakkale \\ *Sorumlu yazar: funda.basarlar@gmail.com
}

Geliş Tarihi: 08.04.2019

Kabul Tarihi: 17.06.2019

\section{$\ddot{O} z$}

Bu çalışma, Çanakkale ili Bayramiç-Çan ilçeleri arasında kalan yaklaşı 50 km'lik alanda yürütülmüştür. Kaz Dağı yöresine ait bu alanda, coğrafi çevre özellikleri açısından yatay ve dikey yönde farklılaşmalar oldukça fazladır. Çalışmada, farklı jeoloji ve jeomorfolojiye sahip kısımlarda incelenen yedi adet toprak profilinin morfolojik tanımlanmasının yanında, her bir horizondan alınan toprak örneklerinde toprakların fizikokimyasal ve bazı mineralojik özelliklerinin (XRD) laboratuvarda incelenmesi amaçlanmıştır. Çan civarında, havza tabanından çevreye doğru Kuvaterner tortullar, Miyosen karasal tortullar, Eosen andezit, Üst paleozoyik şist, fillit, mermer vb. olmak üzere gençten yaşlı arazilere doğru geçilen bir yapı vardır. Bayramiç ve çevresi ise genellikle Miyosen-Pliyosen karasal çökelleri, akarsu düzlükleri, ovalar, alçak ve yüksek platolar, dağlık alanlar ile bu alanlar arasındaki geçiş yüzeylerinden oluşmaktadır. Analiz sonuçlarına göre çalışma alanında en yüksek kil $(\% 47,75)$ ve en yüksek KDK (47 cmol $\mathrm{kg}-1)$ oranı ile eski göl terasında oluşmuş vertisol profilinde saptanmıştır. En derin profil $(160 \mathrm{~cm})$ kolüviyal düzlüklerde oluşmuş alfisol profili, en sı̆̆ ise kireç taşları üzerinde oluşmuş mollisol $(30 \mathrm{~cm})$ profilidir. İncelen profillerin asitlik dereceleri $(\mathrm{pH})$ genellikle nötr ve hafif alkalindir. Organik madde içerikleri yüzey horizonlarında genellikle \%1'den yüksektir. Ancak orman özelliğindeki arazilerde \% 6-11 arasında değişmektedir. Toprak profillerinin bazı horizonlarında X-Işını difraksiyon (XRD) analizleri yapılarak söz konusu toprakların mineralojik bileşimleri hakkında bilgi edinilmiştir. Buna göre kireç taşları üzerinde oluşmuş mollisol profilinde kalsit, kuvars gibi primer mineraller ile paligorskit gibi kil mineralleri saptanmıştır. Kapalı tuzlu göl ortamında oluşmuş vertisol profilinde ise, $\mathrm{SiO}_{2}$ bakımından zengin kuvars ve kristobalit gibi silikat minerallerinin yanında, montmorillonit, zeolit ve illit de saptanmıştır. İncelenen topraklar, laboratuar analiz sonuçları ve morfolojik gözlemler dikkate alınarak Toprak taksonomisi ve WRB sistemine göre sınıflandırılmıştır. Yapılan sınıflamada, araştırma alanı toprakları Toprak taksonomisinin alfisol, mollisol, inceptisol, entisol ve vertisol ordolarında yer almıştır. WRB sınıflandırma sisteminde ise phaozems, luvisols, calcisols, cambisols, fluvisols ve vertisols referans grupları belirlenmiş̧ir.

Anahtar kelimeler: Toprak profili, Horizon, Jeomorfoloji, Çan, Bayramiç

\section{Properties and Classification of the Soils Formed on Different Geological and Geomorphological Lands between Bayramiç-Çan \\ Abstract}

This study was carried out on a terrain, approximately $50 \mathrm{~km}$-long and located between Bayramiç and Çan districts of Çanakkale. This area of Kaz Dağı region has plenty of horizontal and vertical differentiation in terms of geographical characteristics. The study aimed to morphologically identify seven soil profiles that were investigated in sections with varying geology and geomorphology; as well as to analyze physicochemical and some mineralogical characteristics (XRD) of the soil samples taken from each horizon, in laboratory. Çan area possess a structure shifting from younger to older lands as Quaternary sediments, Miocene terrestrious sediments, Eocene andesite, upper Paleozoic schist, phyllite, marble, etc.; expanding out from the bottom of basin. Bayramiç and its vicinity on the other hand, generally consist of Miocene-Pliocene terrestrial deposits, stream flats, plains and high plateaus, mountainsides and transition surfaces among these areas. Based on the analysis results, clay $(50 \%)$ and the highest cation exchange capacity $(50 \mathrm{cmol} \mathrm{kg}-1)$ were detected in profile no.7, composed on the old lake terrace. The deepest profile $(160 \mathrm{~cm})$ was the profile no.2 that formed on colluvial flats, and the shallowest one $(30 \mathrm{~cm})$ was the profile no. 1 that formed on limestones. The degrees of acidity $(\mathrm{pH})$ were generally neutral and mild alkaline. Organic matter contents are generally greater than $1 \%$ in surface horizons. Yet, it varies from 6 to 11 on forest land. By means of XRay Diffraction (XRD) analysis, mineralogical composition was investigated in some horizons of the soil profiles. Calcite, quartz, and palygorskite minerals were detected in profile 1 , which formed on limestones. In profile 8 , which formed in a 
closed salty lake environment, on the other hand, silicate minerals such as $\mathrm{SiO}_{2}$ rich quartz and cristobalite were found along with montmorillonite, zeolite, and illite. Having taken the laboratory results and morphological observations into account, the investigated soils were classified based on soil taxonomy and WRB system. According to the classification soil taxonomy), research area soils were classified asalfisols, mollisols, inceptisols, entisols, and vertisols orders. In WRB sysstems were classified as phaozems, luvisols, calcisols, cambisols, fluvisols and vertisols reference groups.

Key words: Soil profile, Horizon, Geomorphology, Çan, Bayramiç

\section{Giriş}

Topraklar, yerinde değişime uğrayarak ya da diş faktörlerin etkisiyle yüzeyde meydana gelmiş, canlı organizmaları da bulunduran ve bitkilere yaşam kaynağı olan ya da yeryüzünde bulunan tüm varlıkların birikimi olarak tanımlanmaktadır. Bu ifadenin en belirgin fark1, karasal bitkilerin büyümesini sağlayan doğal bir çevre olarak kabul etmesidir (Soil Survey Staff, 1999).

Yağış ve sıcaklık parametrelerinin, topraklarda kimyasal, fiziksel ve biyolojik ayrışmanın çeşidini ve hızını belirleyen en önemli faktörler olduğu bilinmektedir. Bunun yanında yükseklik ve yüzey akışları vejetasyon da kimyasal ayrışmayı etkilemektedir. Toprak genesisi, silikat fraksiyonun parçalanması esnasında bazik katyonların uzaklaşması esasına dayanmakta olup söz konusu bazik katyonların yıkanma ve bitki alımı yolu ile oluşan kaybı mineral ayrışması ile ilişkilidir (Soori ve ark. 2006).

Meksika'da tropikal bir orman alanında jeomorfolojik ve pedojenik özellikler arasındaki ilişkiyi ortaya koymak amacıyla yapılan bir çalışmada, farklı iki jeomorfolojik birim üzerinde oluşmuş toprakların özellikleri araştırılmıştır. İnceleme sonucunda farklı eğimlerde orta düzeyde ayrışmış luvic phaeozem ile zayıf derece oluşmuş fluvic ve skeletic phaeozem toprakları saptanmıştır (Krasilnikov ve ark. (2005).

Eski Konya gölü çevresinde yer alan teraslar üzerinde farklı yaşlardaki profillerde toprak gelişiminin incelenmesi amacıyla yürütülen bir çalışmada, göl çevresinde üst kıyı terasları, ana kıyı terasları ve alt kıyı terasları ile üst kıyı teraslarının üzerinde Kuvarterner ve Neojen yaşlı teraslar üzerinde bulunan profiller incelenmiştir. Bu profillerde toprakların jeokimyasal, fiziksel ve kimyasal özellikleri saptanmış ve elde edilen bulgular söz konusu profillerin zamana bağlı olarak ayrışma derecelerinin karşılaştırılmasında kullanılmıştır. Ayrışma derecelerinin sayısallaştırılmasında CIA, CIW, WIP, PIA, baz $/ \mathrm{R}_{2} \mathrm{O}_{3}$ gibi indeksler, bazı majör ve iz elementlere ait genetik oranlar kullanılmıştır. Araştırma sonucunda toprakların farklı yaşı teraslar üzerinde oluşmalarına rağmen pedokimyasal aktivitelerinin oldukça benzer olduğunu ortaya konulmuştur (Mutlu, 2010).

Dengiz ve Efendiler (2016, )Samsun-Çarşamba ilçesi Bölmepınar ve Yenikışla köylerinin ve yakın çevresinde yoğun tarım yapılan Yeşil ırmak tarafindan farklı zamanlarda depolanmış alluviyal depozitler üzerinde oluşmuş fluviyal yer şekilleri ile yamaç araziler üzerinde oluşmuş toprakların dağılımlarını belirlemek, haritalandırmasını yapmak ve farklı toprakları sınıflamak amaciyla 8 adet profil açılmışlardır. Araştırıcılar, detaylı arazi gözlemleri ve laboratuvar analizlerine göre araştırma topraklarını Entisol, Veritisol, ve Inceptisol ordolarında sınıflandırmış, en önemli arazi ve toprak sorunlarını, yamaç arazilerin yer aldığı alanlarda eğim, erozyon ve torak derinliği oluştururken, taban arazilerde ise ağır bünyeli olan topraklarda zayıf drenaj, kaba bünyelerin dağılım gösterdiği alanlarda ise düşük su tutma kapasitesi ve aşırı drenaj olarak belirlemişlerdir.

Pamuk ve Ekinci (2018), Çan (Çanakkale) yöresinde toprak-su haritalarında yaygın olarak yer alan büyük toprak gruplarının önemli özelliklerini ortaya koymak ve sınıflandırmak amacıyla yürüttükleri çalışmada, araştırma alanı topraklarında yarayışlı demir $(\mathrm{Fe})$, mangan $(\mathrm{Mn})$ ve bakır $(\mathrm{Cu})$ içeriklerini yeterli, çinko (Zn) içeriklerini ise genellikle düşük seviyede bulmuşlardır.Söz konusu çalışmada, incelenen profillerden 2 ve 4 no'lu profiller Toprak Taksonomisine göre Mollic Haploxeralfs, 1 no'lu profil Typic Haploxerolls, 3 no'lu profil Cumulic Humixerepts ve 5 no'lu profil ise Fluventic Haploxerolls olarak sinıflandırılmıştır.

Amerikan Eski Toprak sınıflama sisteminde dikkate alınan morfogenetik yaklaşıma göre Çan'da kahverengi orman, kireçsiz kahverengi orman, kollüvyal ve rendzina toprakları gibi büyük toprak grupları vardır (Anonim, 1999). Kireç içermeyen kahverengi orman topraklarında toprak profili A (B) ve $\mathrm{C}$ horizonlarını içermektedir. Bayramiç ve çevresinde kahverengi orman toprakları, kireçsiz kahverengi orman toprakları ve alüviyal büyük toprak grupları bulunmaktadır (Yüksel ve Ekinci, 2008). 
Çan ve Bayramiç ilçeleri arasındaki alanda yapılan bu çalışmada, bölge üzerinde oluşmuş farklı profil özelliklerine sahip topraklar saptanarak, bunları temsil edebilecek profillerin incelenmesi ve morfometrik yaklaşıma göre sınıflandırılması amaçlanmıştır.

\section{Materyal ve Yöntem}

\section{Çalışma Alanı}

Çalışma, Çanakkale ili Bayramiç-Çan İlçeleri arasındaki yaklaşık 50 km'lik alan içerisinde incelenen yedi adet toprak profili üzerinde yürütülmüştür (Şekil 1). Açılan her bir profilin farklı horizonlarından alınan 32 adet toprak örneği temel materyal olarak kullanılmıştır.

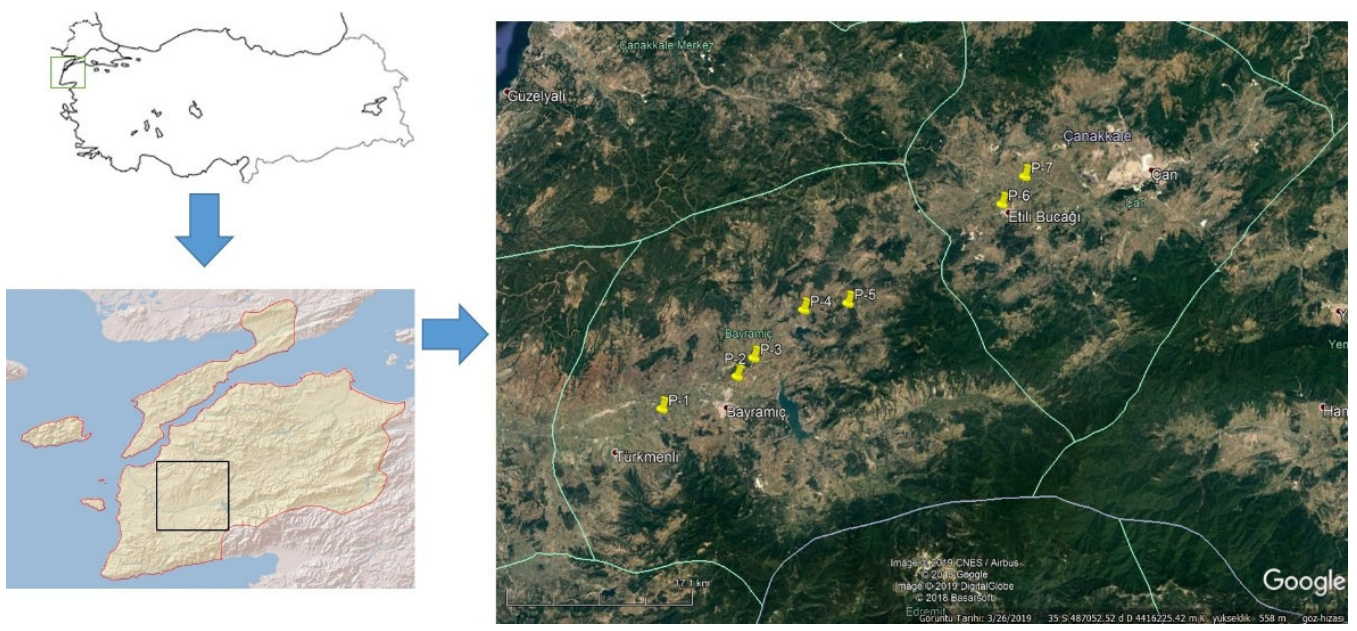

Şekil 1. Çalışma alanının coğrafi konumu ve incelenen toprak profillerinin yerleri

\section{İklimi ve Özellikleri}

Çan ve Bayramiç ilçelerinin iklimi, Akdeniz iklim tipine yakındır. Yaz ayları oldukça sıcak ve kurak, kışlar yağışlı ve soğuktur. Genel olarak temmuz, ağustos ve eylül aylarında yağış görülmemektedir. Çanakkale'nin yıllık yağış miktarı $655 \mathrm{~mm}$, yıllık ortalama sıcaklık ise $14.2{ }^{\circ} \mathrm{C}$ dir. Ortalama toprak sıcaklığı $\left(50 \mathrm{~cm}\right.$ de) $16.9{ }^{\circ} \mathrm{C}^{\prime} \mathrm{dir}$ (Anonim, 1999). Çan ikliminin genellikle Akdeniz ve Karadeniz iklim özelliklerini yansıttığı görülmektedir. Kuzey rüzgarları daha etkili olmakta ve yağışların en fazla görüldüğü aylar sonbahar, kış ve ilkbahar aylarıdır (Anonim, 2012 ).

\section{Doğal Bitki Örtüsüi}

Çanakkale il yüzölçümünün \%55'i ormanlık alandan oluşmaktadır. Kalan alanlar ise tarıma elverişli araziler, çayır ve meralardan oluşmaktadır. Bölgede Akdeniz iklimine özgü maki, defne, mersin, kocayemiş ve çalılık bitki toplulukları görülmektedir. Hakim olan ormanlık alanlarda farklı cins ağaç toplulukları bulunmaktadır. Bölgenin iç kısımlarında su boylarında hemen hemen her mevsim yeşil olan çayırlar, tahıl üretimine elverişli alanlar, cılız otlu ve bozkır görünümlü alanlara da rastlanabilmektedir (Anonim, 2016 ).

\section{Jeoloji ve Jeomorfolojisi}

Havza tabanından çevreye doğru Kuvaterner çökeltileri, Miyosen karasal çökeltileri, Oligosen bozulmamış volkanik, Eosen volkanik, Eosen andezit, Üst paleozoik (şist, fillit mermer vb.) yapılar mevcuttur. Bu yapı genç topraktan yaşlı topraklara doğru oluşan bir durumdur. Bölgenin jeolojik yapısında, drenajın şekillenmesinde ve yer şekillerinde bölgede bulunan faylar belirleyici bir etken oluşturmuş olup bu alanda kancalı drenajın tipik örnekleri görülür (Bozcu ve Çalık, 2006). Bayramiç ve çevresi Miyosen-Pliyosen kıtasal çökellerinden oluşmuştur (Yılmaz, 2001). Bu alanlar, akarsu çevresi düzlükleri, ovalar, alçak platolar, yüksek platolar, dağlik alan ile bu alanlar arasındaki geçiş yüzeylerinden oluşmaktadır.

\section{Yöntem}

Çalışma alanında saptanan yedi farklı toprak profilinden toprak örnekleri, genetik horizon esasına göre alınmış, toprakların morfolojik özelliklerinin arazide incelenmesi amacıyla dikkate alınacak kriterler, örneklemeler Soil Survey Staff (1993)'de belirtilen esaslara göre 
gerçekleştirilmiştir. Toprak profilleri, Toprak Taksonomisi (Keys to Soil Taxonomy 2014) ve WRB toprak sinıflandırma sistemine (IUSS, 2014) göre sınıflandırılmıştır

Tekstür tayini: Bouyoucos (1951)'e göre hidrometre metoduyla analize tabi tutulmuştur.

Elektriksel iletkenlik (EC): Elektriksel iletkenlik (EC) analizi WTW-LF320 marka EC metre ile 1:2,5 oranında toprak-su karışımında ölçülmüştür (Anonymous, 1951; Richards, 1954).

Toprak reaksiyonu (pH): Çalışma alanında profillerden alınan topraklarda, $\mathrm{pH}$ değerleri HACH HQ40d marka pH-metre kullanılarak 1:2,5 toprak-saf su süspansiyonunda belirlenmiştir (Richards, 1954; Grewelling ve Peech, 1960).

Kireç (\% $\left.\mathrm{CaCO}_{3}\right)$ : Scheibler Kalsimetresi ile volümetrik olarak belirlenmiştir (Schlichting and Blume, 1966).

Organik madde: Smith-Weldon yaş yakma yöntemi ile belirlenmiştir (Sağlam, 2008).

Katyon değişim kapasitesi (KDK): Sodyum asetat ekstraksiyonu yöntemi ile belirlenmiştir (U.S. Salinity Lab. Staff, 1954).

Mineralojik analizler: Çalışma alanından alınan toprak numunelerinin XRD analizleri ÇOMÜ Merkez Laboratuvarında (ÇOBİLTUM), X-Işını Kırınım difraksiyonu metoduna göre belirlenmiştir (Whitting, ve Allardice, 1986). Bunun için; PANakytical Empyrean cihazı kullanılmış ve $5^{\circ}-70^{\circ}(2 \theta)$ arasında X-ray $(\lambda=1.54056 \AA, 45 \mathrm{kV}$ ve $40 \mathrm{~mA})$ çekimleri yapılarak veriler X'Pert High Score Plus software yazılımında değerlendirilmiştir.

\section{Bulgular ve Tartışma}

Çalışma alanında incelen toprak profillerinin görünümleri Şekil 2'de, bazı fiziksel ve kimyasal analiz sonuçları ise Çizelge 1'de sunulmuştur.

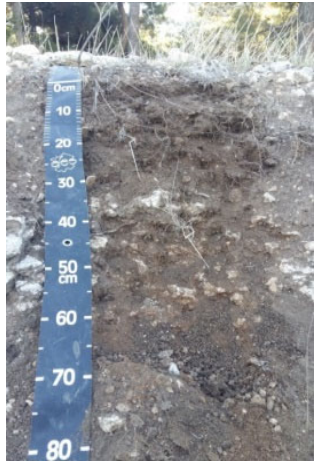

P1

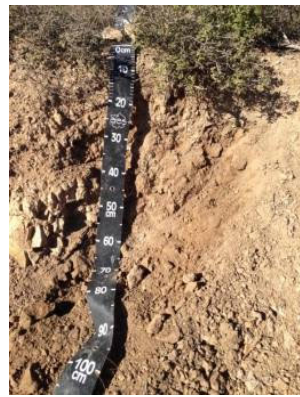

P 5

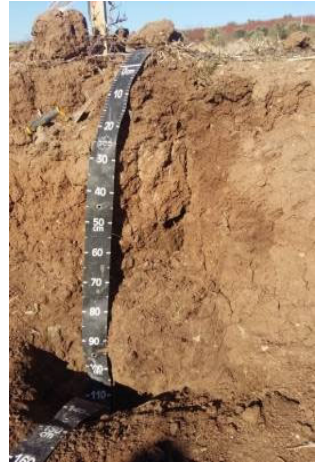

P 2

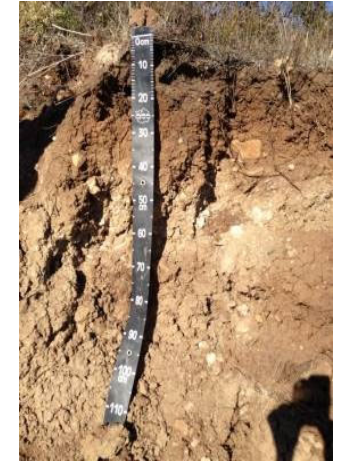

P 3

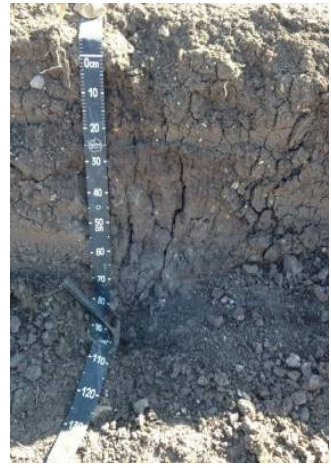

P 4

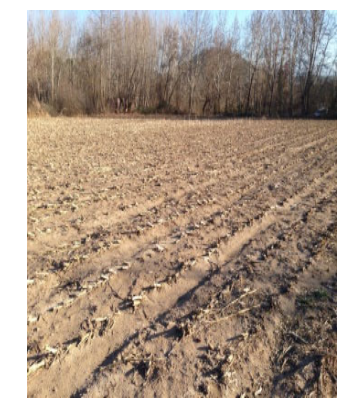

P 6 (çevresi)

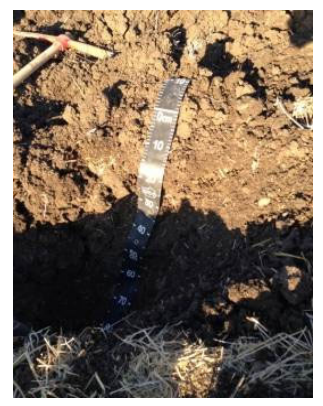

P7

Şekil 2. Çalışma alanında incelenen toprak profillerinin görünümü

Toprak taksonomisine göre Lithic Haploxerolls olarak sınıflandırılan 1 no'lu profil, eski kapalı göl teraslarında ve üst pliosen yaşlı kireç taşları üzerinde oluşmuştur. Eğim \% 2-4 arasında ve denizden yüksekliği 96 metredir. Renkleri kuru iken profil boyunca kırmızımsı kahverengi (2,5 YR 5/3) dir. Profil 1'in $\mathrm{pH}$ değeri yüzeyde 7,88 iken alt horizonlarda 8,01'e yükselmektedir. Profil boyunca çok fazla kireçli olup kireç miktarı \%30 civarındadır. Katyon değişim kapasitesi 33,5-29,7 
ÇOMÜ Zir. Fak. Derg. (COMU J. Agric. Fac.)

2019: 7 (1): 69-80

ISSN: $2147-8384$ / e-ISSN: 2564-6826

doi:10.33202/comuagri.550835

cmol $\mathrm{kg}^{-1}$ arasında değişmektedir. Organik madde içerikleri profil boyunca yüksek olup \% 8 civarındadır. Yüzeyde \%72,43 olan kum içeriği alt katmanda \%57,78'e düşmekte; yüzeyde \%17,9 olan kil içeriği alt horizonda \%25,29' a yükselmektedir. Toprak bünyesi yüzeyde kumlu tın, yüzey altında ise kumlu kil tındır.

Çizelge 1. Çalışma alanı topraklarının bazı fiziksel ve kimyasal analiz sonuçları

\begin{tabular}{|c|c|c|c|c|c|c|c|c|c|c|c|}
\hline \multirow[b]{3}{*}{1} & A1 & $0-20$ & 7,88 & 338 & 30 & 8,33 & 33,5 & 72,43 & 9,67 & 17,9 & SL \\
\hline & A2 & $20-30$ & 8,01 & 373 & 29,4 & 7,21 & 29,7 & 57,78 & 16,73 & 25,29 & SCL \\
\hline & $\mathrm{Cr}$ & & & & & & & & & & \\
\hline \multirow{8}{*}{2} & Ap & $0-16$ & 7,55 & 229 & 1,4 & 1,69 & 27 & 68,81 & 17,15 & 20,04 & SCL \\
\hline & A2 & $16-30$ & 7,45 & 140 & 1,5 & 0,92 & 28,7 & 73,36 & 5,94 & 20,70 & SCL \\
\hline & AB & $30-55$ & 7,65 & 170 & 1,6 & 0,71 & 30 & 64,07 & 8,33 & 27,60 & SCL \\
\hline & Bt1 & $55-70$ & 7,81 & 207 & 1,7 & 0,59 & 35,5 & 61,87 & 4,01 & 34,12 & SCL \\
\hline & $\mathrm{Bt} 2$ & $70-95$ & 7,7 & 222 & 2,2 & 0,60 & 35,5 & 51,90 & 13,27 & 34,83 & SCL \\
\hline & $\mathrm{Bt3}$ & $95-125$ & 7,8 & 241 & 2,3 & 0,43 & 35,5 & 54,46 & 10,23 & 35,31 & $\mathrm{SC}$ \\
\hline & $\mathrm{BC}$ & $125-160$ & 8,25 & 310 & 8,46 & 0,11 & 34,4 & 62,85 & 10,45 & 26,70 & SCL \\
\hline & $\mathrm{C}$ & $160+$ & 8,33 & 327 & 34,98 & 0,15 & 32 & 65,95 & 13,04 & 21,03 & SCL \\
\hline \multirow{5}{*}{3} & A1 & $0-18$ & 7,45 & 437 & 2,17 & 6,79 & 26,5 & 77,72 & 9,29 & 12,99 & SL \\
\hline & $\mathrm{A} 2$ & $18-30$ & 7,46 & 356 & 1,6 & 1,90 & 26 & 64,18 & 15,36 & 20,46 & SCL \\
\hline & $\mathrm{AC}$ & $30-40$ & 7,61 & 343 & 10,35 & 1,13 & 19 & 72,65 & 15,55 & 11,18 & SL \\
\hline & $\mathrm{Ck}$ & $40-75$ & 7,76 & 383 & 35,31 & 0,64 & 29 & 55,63 & 17,05 & 27,28 & SCL \\
\hline & $\mathrm{C}$ & $75+$ & 8,01 & 375 & 19,41 & 0,54 & 26 & 47,14 & 24,55 & 28,31 & SCL \\
\hline \multirow{5}{*}{4} & Ap & $0-16$ & 7,2 & 310 & 3,63 & 1,31 & 29,5 & 43,27 & 26,11 & 30,62 & $\mathrm{CL}$ \\
\hline & $\mathrm{A} 2$ & $16-35$ & 7,87 & 262 & 3,48 & 1,26 & 28 & 58,98 & 14,94 & 26,08 & SCL \\
\hline & $\mathrm{AB}$ & $35-45$ & 7,9 & 296 & 3,95 & 0,78 & 31 & 50,48 & 12,05 & 37,47 & SCL \\
\hline & $\mathrm{Bw}$ & $45-80$ & 8,22 & 301 & 5,85 & 0,36 & 30 & 47,01 & 17,05 & 35,95 & $\mathrm{SC}$ \\
\hline & $\mathrm{BC}$ & $80+$ & 8,25 & 391 & 5,22 & 0,22 & 31 & 48,24 & 13,21 & 38,55 & SCL \\
\hline \multirow{4}{*}{5} & $\mathrm{Ap}$ & $0-19$ & 7,94 & 243 & 1,18 & 11,12 & 29 & 75,06 & 19,62 & 5,32 & LS \\
\hline & A2 & $19-26$ & 7,85 & 170 & 2,45 & 6,72 & 21 & 68,64 & 19,44 & 11,92 & SL \\
\hline & $\mathrm{CR}$ & $26-39$ & 7,45 & 191 & 1,97 & 2,11 & 19 & 66,79 & 17,67 & 15,54 & SL \\
\hline & $\mathrm{R}$ & $39+$ & & & & & & & & & \\
\hline \multirow[b]{3}{*}{6} & Ap & $0-20$ & 6,97 & 315 & 1,26 & 2,18 & 23 & 70,45 & 13,15 & 16,04 & SL \\
\hline & $\mathrm{A} 2$ & $20-40$ & 7,4 & 245 & 1,66 & 2,11 & 25 & 71,4 & 9,98 & 18,62 & SL \\
\hline & $\mathrm{C}$ & $40+$ & & & & & & & & & \\
\hline \multirow[b]{4}{*}{7} & Ap & $0-20$ & 7,2 & 466 & 1,66 & 2,67 & 32 & 42,57 & 16,06 & 41,37 & $\mathrm{C}$ \\
\hline & A2 & $20-40$ & 7,6 & 430 & 7,11 & 1,35 & 43 & 36,34 & 21,13 & 42,53 & $\mathrm{C}$ \\
\hline & A3 & $40-70$ & 7,68 & 280 & 8,54 & 1,38 & 36 & 37,70 & 21,45 & 40,85 & $\mathrm{C}$ \\
\hline & $\mathrm{AC}$ & $70+$ & 7,49 & 695 & 8,7 & 1,51 & 47 & 31,33 & 20,92 & 47,75 & $\mathrm{C}$ \\
\hline
\end{tabular}

Kolüviyal arazilerin alt etek düzlüklerinde (eğim \%0-2) ve denizden 113 m yükseklikte oluşmuş 2 nolu profil toprakları Typic Haploxeralfs olarak sınıflandırılmıştır. Renkleri, kuru iken yüzeyde sarımsı kahverengi (10 YR 5/4, yüzey altında koyu kahverengi (7.5YR 3/2,) dir. Profil 2'nin pH değeri üst horizonda 7,55 iken alt horizonlarda. 8,25'e (BC) yükselmiştir. Kireç durumu üst katmandan BC horizonuna kadar az kireçli iken $\mathrm{BC}$ horizonunda orta kireçli $\mathrm{C}$ horizonunda ise çok fazla kireçlidir. Profil boyunca organik madde içeriği ise çok azdır. Katyon değişim kapasitesi profil boyunca 35,5-27 cmol kg-1 arasında değişmektedir. Yüzeyde \%20,04 olan kil içeriği alt katmanlara doğru artış göstermiş ve Bt3 horizonunda \%35.31 yükselmiştir. Toprak bünyesi kumlu kil tın ve kumlu kil'dir.

Yamaç arazilerde marn ana materyali üzerinde, denizden $190 \mathrm{~m}$ yükseklikte ve \%2-5 eğimde oluşmuş 3 no'lu profil toprakları toprak taksonomisine göre Typic Calcixerolls olarak sınıflandırılmıştır. Renkleri, yüzeyde kuru iken koyu grimsi kahverengi (10 YR 4/2,) yüzey altında sarımsı kahverengi (10 YR 5/4)'dir. Profil 3'ün $\mathrm{pH}$ değeri ilk horizondan itibaren 7,45 civarında iken son katmanda 8,01 'e yükselerek değişim göstermiştir. İlk iki horizon az kireçli (sırasıly \% 2,17 ve 1,6) iken kireç içeriği $\mathrm{Ck}$ horizonunda \%35,31'e yükselmiştir. Yüzeyde \% 6,79 değeri ile çok fazla olan organik madde miktarı alt horizonlarda çok az miktardadır. Yüzeyde $26,5 \mathrm{cmol} \mathrm{kg}^{-1}$ olan katyon değişim kapasitesi (KDK), alt horizonlarda $29 \mathrm{cmol} \mathrm{kg}^{-1}$ 'a kadar artmaktadır. Kum içeriği yüzeyde $\% 77,7$ iken C horizonunda \%47'ye düşmekte; kil içeriği yüzeyde \%13 iken yine C horizonunda \%28'e yükselmektedir. Toprak bünyesi yüzeyde kumlu tın, yüzey altında kumlu kil tındır. 
Yüksek arazilerin \% 2-4 eğimli (rakım 195 m), killi-kireçli çamur akıntıları üzerinde oluşan 4 no'lu profil Vertic Haploxerepts olarak sınıflandırılmıştır. Renkleri, yüzeyde kuru iken koyu gri (10 YR 4/1), yüzey altında koyu kahverengi (7,5 YR 3/2), yüzey altında kahverengi (7,5 YR 4/2 )'dir. Profil 4'ün pH değeri ilk iki horizonda 7,87 iken alt horizonlarda 8'in üzerine çıkmıştır. Üst horizonlar az kireçli iken alt horizonlar orta kireçlidir $(\% 5,85)$. Organik madde miktarı, yüzeyden itibaren tüm profilde düşük veya çok azdır. Katyon değişim kapasitesi (KDK), profil boyunca $30 \mathrm{cmol} \mathrm{kg}^{-1}$ civarındadır. Yüzeyde $\% 43,27$ olan kum içeriği son horizonda \%48,24'e, yüzeyde \%30,62 olan kil içeriği de son horizonda \%38,55'e yükselmiştir.

Lithic Haploxerolls olarak sınıflandırılan ve çam fidanlığında incelen profil 5, yüksek arazi düzlüğünde ve andezitik bir sahada, \% 2-3 arasında değişen bir eğimde (rakım $272 \mathrm{~m}$ ) oluşmuştur. Renkleri, kuru iken yüzeyde koyu kahverengi (7,5 YR 3/2), yüzey altında kahverengi (7,5 YR 5/4)'dir. Profil 5 tüm horizonlarında az kireçli durumdadır. $\mathrm{pH}$ değeri üst horizonda 7,94 iken alt horizona doğru 7,45'e düşmüştür. Organik madde miktarı yüzeyde \%11,12 değeri ile çok fazla, alt horizonda ise orta $(\% 2,11)$ seviyededir. Katyon değişim kapasitesi yüzeyde $29 \mathrm{cmol} \mathrm{kg}^{-1}$ iken, yüzey alında azalarak Cr horizonunda $19 \mathrm{cmol} \mathrm{kg}^{-1}$ 'e düşmektedir. Kum içeriği tüm profilde $\% 65$ 'in üzerinde olup toprak bünyesi yüzeyde tınlı kum yüzey altında kumlu tındır. Yüzeyde $\% 5,32$ olan kil içeriği ise alt horizonda \% 15,54 'e yükselmiştir.

Genç alüviyal nehir terasında incelen ve Typic Xerofluvent olarak sınıflandırılan 6 no'lu profilde tuzluluk ve drenaj sorunu bulunmamaktadır. Renkleri kuru iken kahverengi veya sarıms1 kahverengi (10 YR 4/3) dir. Profil 6, ortalama \%1,46 kireç içerikleriyle az kireçli sınıfındadır. pH değeri Ap horizonunda 6,97, A2 horizonunda 7,4'tür. Profil boyunca organik madde miktarı \% 2'nin üzerinde olup katyon değişim kapasitesi ortalama $24 \mathrm{cmol} \mathrm{kg}^{-1}$ civarındadır. Kum içerikleri \% $\%$, kil içerikleri ortalama \% 17 olan profil 6'nın toprak bünyesi kumlu tındır.

Eski kapalı göl depozitlerinin \%2-4 eğimli (rakım 159 m) yüzeylerinde oluşan 7 no'lu profile ait topraklar, Chromic Haploxererts olarak sınıflandırılmıștır. Renkleri kuru iken, yüzeyde koyu veya çok koyu grimsi kahverengi (10 YR 3/2) dir. Profil 7'nin üst horizonunda kireç değeri \%1,66 ile az kireçli, alt horizonlarda ise \%7'nin üzerine çıkmakta ve orta kireçli durumdadır. $\mathrm{pH}$ değeri yüzeyde 7.2, A3 horizonunda 7,68' dir. Organik madde miktarı Ap horizonunda \%2,66 değeri ile orta, diğer horizonlarda ise az seviyededir. Ap horizonunda $32 \mathrm{cmol} \mathrm{kg}^{-1}$ olan katyon değişim kapasitesi, alta doğru kil artışına paralel olarak artmakta ve AC horizonunda $47 \mathrm{cmol} \mathrm{kg}^{-1}$ 'a ulaşmaktadır. Profilleri boyunca kil içeriği \% 40’ı üzerinde olup toprak bünye sınıfı kildir.

Çizelge 1'de görüldüğü üzere çalışma alanında en derin profil $(160 \mathrm{~cm})$ kolüviyal düzlüklerde oluşmuş 2 no'lu profil, en sı̆ ise kireç taşları üzerinde oluşmuş 1 no'lu $(30 \mathrm{~cm})$ profildir. Yapılan analiz sonuçlarına göre organik madde içerikleri yüzey horizonlarında genellikle \%1'den yüksektir. Orman özelliğindeki arazilerde \% 6-11 arasında değişmektedir. Çalışma alanında en yüksek kil (\%47.75) ve en yüksek KDK (47 cmol kg-1 ) oranı ile eski göl terasında oluşmuş 7 no'lu profilde saptanmıştır. Araştırma profillerinin asitlik dereceleri $(\mathrm{pH})$ genellikle nötr ve hafif alkalindir.

Profillerin yüzey horizonlarına ait XRD difraktogramları Şekil 3`de, profillere ait bazı horizonların XRD sonuçlarına dayalı mineral içerikleri ise Çizelge 2' de sunulmuştur. Söz konusu profillerde kalsit, kuvars, feldspat ve mikalar en çok saptanan mineraller olmuştur. Bunların yanında montmorillonit ise en bol rastlanan kil minerali olarak belirlenmiştir. 
ÇOMÜ Zir. Fak. Derg. (COMU J. Agric. Fac.)

2019: 7 (1): 69-80

ISSN: $2147-8384$ / e-ISSN: 2564-6826

doi:10.33202/comuagri.550835

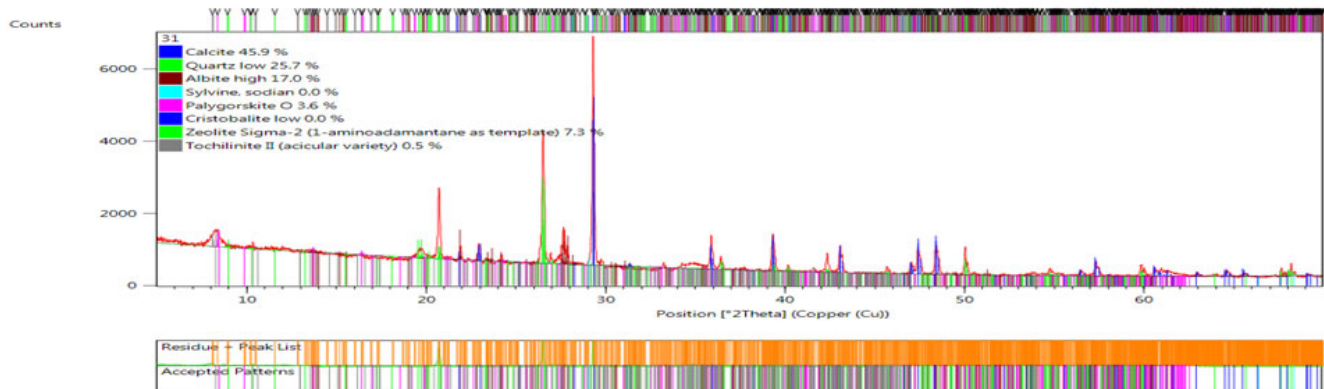

P1 A1

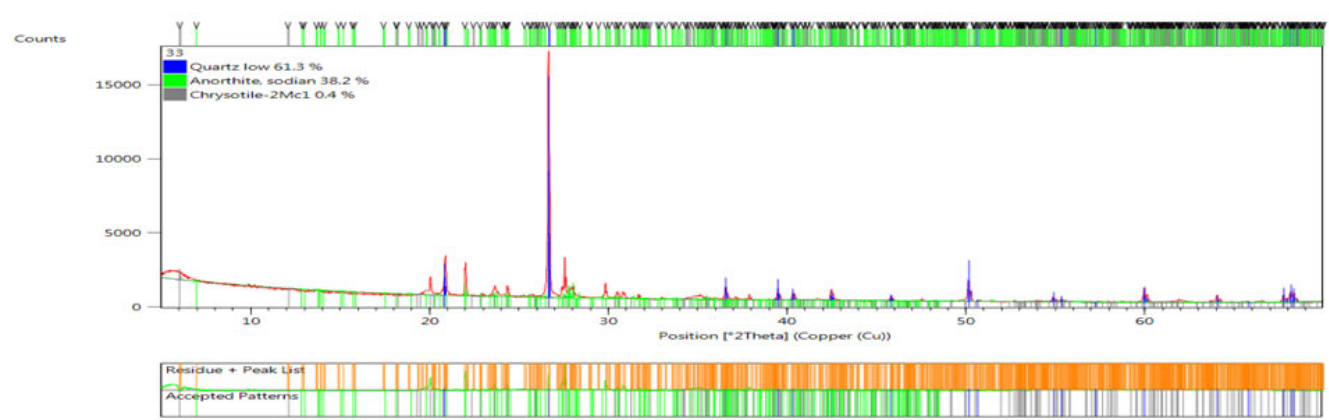

P2 Ap
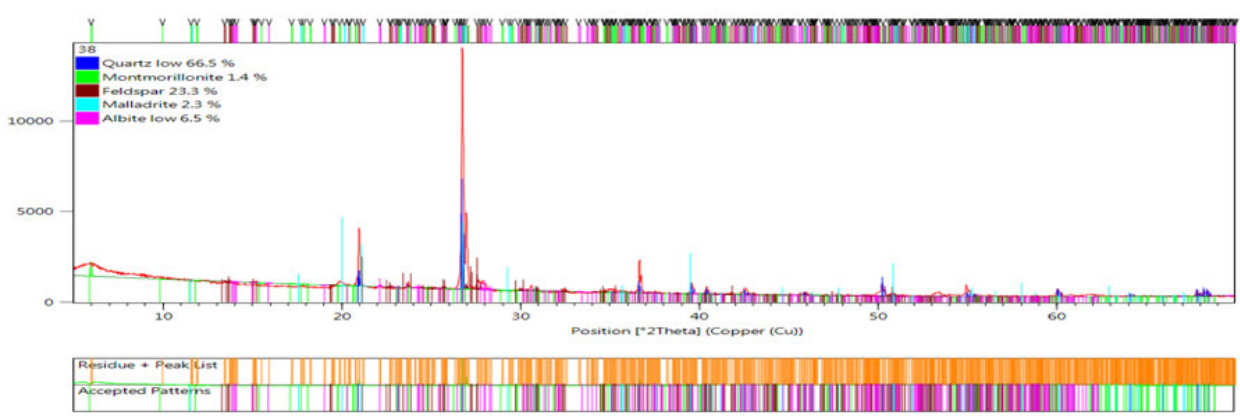

P3 A1
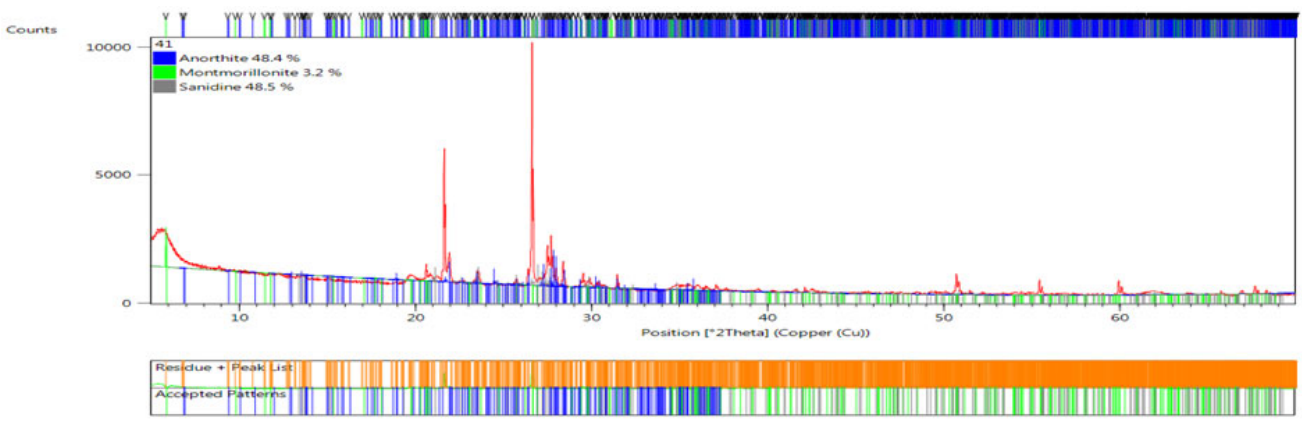

Şekil 3. İncelenen profillerin yüzey horizonlarına ait XRD difraktogramları 
ÇOMÜ Zir. Fak. Derg. (COMU J. Agric. Fac.)

2019: 7 (1): 69-80

ISSN: $2147-8384$ / e-ISSN: 2564-6826

doi:10.33202/comuagri.550835

Şekil 3’ün devamı
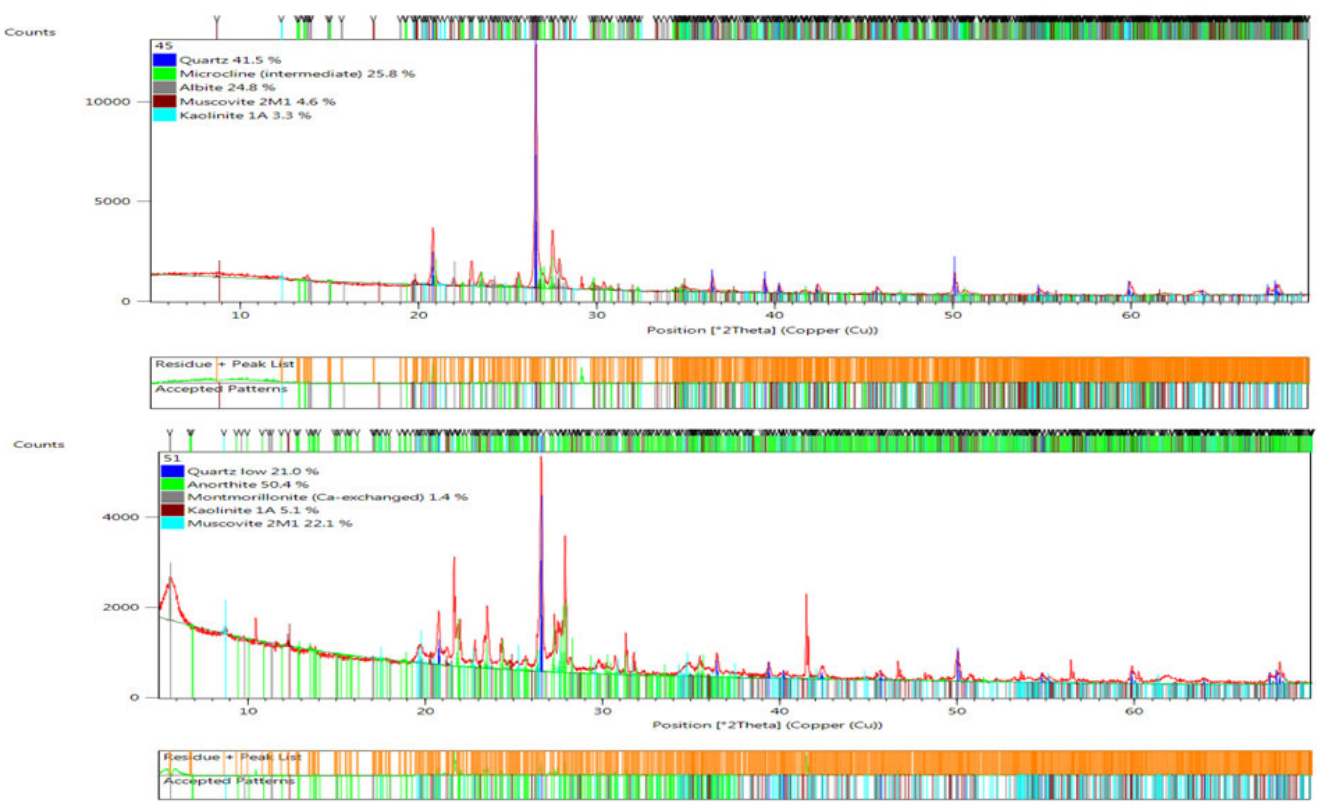

P5A1

Ap

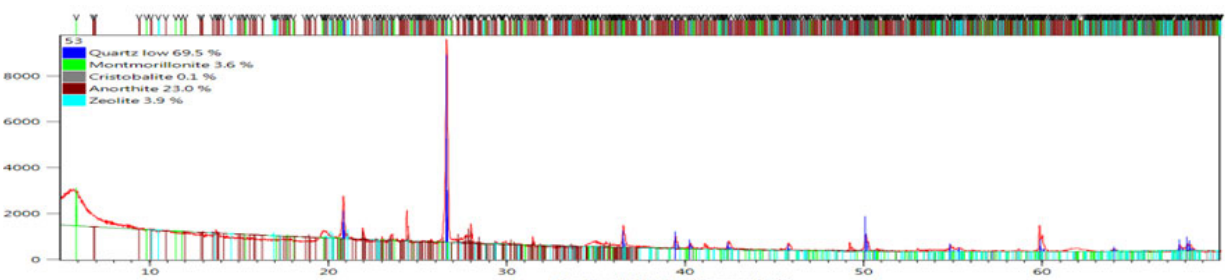

Ap

Çizelge 2. İncelenen profillerin XRD analizlerine göre belirlenmiş mineralojik bileşimleri

Profil No HorizonDerinlik(cm)

Profil $1 \quad 0-20$

A2 $20-30$

Profil 2

Ap $\quad 0-16$

Bt3 95-125

C $160+$

Profil $3 \quad$ A1 $\quad 0-18$

Ck $\quad 40-75$

Profil 4

$\begin{array}{ll}\mathrm{Ap} & 0-16 \\ \mathrm{Bw} & 45-80 \\ \mathrm{BC} & 80+\end{array}$

Profil 5

A1 $\quad 0-19$

$\mathrm{Cr} \quad 26-39$

Profil 6

Ap

$0-20$
Kuvars, albit, kaolinit, kalsit, sylvine, paligorskit, kristobalit, zeolit, tochilinit

Kalsit, kuvars, kristobalit, albit, sylvine, paligorskit

Kuvars, anortit, krisotil

Kuvars, krisotil, albit, feldspat, muskovit

Kalsit, kuvars, montmorillonit, anortit, krisotil

Kuvars, montmorillonit, feldspat, malladrit, albit Kalsit, kuvars, zeolit, magnetit, montmorillonit, klintonit Anortit

Anortit, montmorillonit, sanidin

Kalsit, tridmit, montmorillonit, kristobalit, anortit, kristobalit

Kalsit, kristobalit, anortit, montmorillonit

Kuvars, mikroklin, albit, muskovit, kaolinit

Kuvars, ortoklas, albit, kaolinit, muskovit

Kuvars, anortit, montmorillonit, kaolinit, muskovit 


\section{Çalışma Alanı Topraklarının Oluşumu}

Profil 1, kapalı göl ortamında çökelmiş, üst pliosen yaşlı kireç taşları üzerinde oluşmuş AC horizonlu topraklardır. Yüzeyde orman örtüsü nedeniyle organik madde miktarı yüksek olup (\%8.33) iyi ayrışmış durumdadır. Mineral A horizonu organik madde nedeniyle koyu renkli ve $30 \mathrm{~cm}$ kalınlıktadır. Profilde eğim ve erozyona bağlı nedenlerle horizonlaşma yoktur, sı̆̆ ve genç topraklardır. X-Işını difraksiyon (XRD) analiz sonuçları incelendiğinde A1 ve A2 horizonlarında kalsit ve kuvars minerallerinin oldukça yüksek miktarda bulunduğu görülmektedir (Çizelge 2). Bunun yanında albit, ve paligorskit gibi minerallerin de bulunduğu saptanmıştır. Söz konusu minerallerin tamamının ana materyalden (kireç taşı) kalıtsal yolla gelen mineraller olması, profil 1 'de ayrışmanın düşük seviyede olduğunu göstermektedir. Bu profilde saptanan paligorskit minerali, göl ortamında ve alkali koşullarda kireç taşları içerisinde oluşmuş olmalıdır. Nitekim Yılmaz (1999), Harran ovasında yaptığı çalışmada, paligorskitin ovadaki Cepkenli ve Hancıgaz gibi eski göl tabanı topraklarında ve Miyosen tepecikler üzerinde oluşmuş Akören serisinde baskın durumda olduğunu saptamıştır. Araştırıcı paligorskitin dünyada daha çok kireç taşları ve benzer materyaller üzerinde gelişmiş kurak ve yarı kurak bölgelerde yaygın olduğunu belirtmiştir. Ergene (1963), Gaziantep civarında kireç taşları üzerinde gelişmiş toprakta paligorskit mineralini saptamıştır.

Profil 2, bulunduğu konumun üst kısımlarında \%8-10'a varan eğime bağlı olarak taşınan kolüviyal malzemelerin depolandığı, yaşı, alt etek düzlüklerinde oluşmuş derin profil yapısına sahip A-B-C horizonlu topraklardır. A horizonundan yıkanan kil, alt kısımlara taşınarak kalın argillik B horizonlarını oluşturmuştur. Arazi gözlemleri ile saptanan bu durum, laboratuvar analiz sonuçları ile de doğrulanmıştır (Çizelge 1). Bunun yanında kuvvetli yarı köşeli blok strüktür belirlenmiştir. XRD analiz sonuçları incelendiğinde, ana materyalden itibaren çeşitli minerallerin (kuvars, montmorillonit, krisotil, albit, anortit, kalsit, muskovit gibi) varlığı, söz konusu profilin karışık materyaller (kolüviyal) üzerinde oluştuğunu göstermektedir (Şekil 3, P1). Ap, Bt3 ve C horizonlarında kuvars mineralinin fazla olduğu, kalsitin ise $C$ horizonunda bulunup üst horizonlarında bulunmaması, söz konusu üst horizonlarda ayrıştığını göstermektedir. Bunun yanında feldspat ve muskovitin yüzeyde ayrışttğg ve yüzey altında da ayrışmakta olduğu anlaşılmaktadır (Çizelge 2).

Profil 3'te organik maddenin yüzeyde ayrıştığı, A-C horizon diziliminin görüldüğü genellikle marn üzerinde oluşmuş topraklardır. Bu profilde, kireç içeriği yüksek kalsik horizon (Ck) oluşmuştur. Profilin alt kısımlarındaki kalsitin, bikarbonatların alt kısımlara yağış suları ile taşınması ve pH'nın yükselmesi sonucunda $\mathrm{Ck}$ horizonunda karbonatların çökelmesi ile oluştuğu düşünülmektedir. Alt katmanlarda zeolit ve montmorillonit kil minerali de saptanmıştır. Sayın (1999)'a göre Türkiye topraklarında yağışın 1000 mm'nin altında bulunması ve pH'nın da 7-8 arasında bulunması, toprak çözeltisinde hakim katyonun kalsiyum (Ca) olması, smektit grubu killerin kararlılığını sağlamaktadır. Aynı araştırıcı tarım topraklarında iyon değiştirici özelliği ile önemli bir mineral olan zeolitin feldspat, kalsit gibi birincil minerallerin ayrışması sonucunda oluşan alkali ortamda çökelebildiğini belirtmektedir.

Profil 4 hafif eğimli yamaçlarda, killi ve kireçli çamur akıntıları üzerinde oluşmuş A-B-C horizon dizilimine sahip topraklardır. Yyakın konumlarda andesitik materyaller çokça bulunmaktadır. Topoğrafik koşullara bağlı olarak hafif derecede su erozyonu etkisindedirler. Yüzeyde granüler, yüzey altında orta ve çoğunlukla kuvvetli yarı köşeli blok strüktüre sahiptirler. Altta orta-kuvvetli derecede gelişmiş blok strüktür ve kil birikiminin olduğu kambik $(\mathrm{Bw})$ horizon oluşmuştur. XRD difroktogramından anlaşıldığ 1 gibi bileşimleri genellikle ana materyal ile farklı noktalardan taşınmış kil ve kireçli materyaller içerisindeki feldspatlardan oluşmaktadır (Şekil 3, Çizelge 2). Ap horizonunda yüksek miktarda anortit ve sanidinin yanında az miktarda montmorillonit bulunmaktadır. Bunlardan anortit (Ca feldspat) ve sanidin ( yüksek sıcaklıkta oluşmuş K-feldspat) \% 48 civarında bir orana sahiptir. $\mathrm{Bw}$ ve $\mathrm{BC}$ horizonlarında feldspatların bir kısmının kile altere olduğu düşünülmektedir.

Profil 5 yüksek arazi düzlüklerinde ve hafif eğimli yamaçlarda andezitik materyaller üzerinde oluşmuş A-C horizonlu topraklardır. Yüzeyde organik maddece zengin A1 horizonu bulunmaktadır. $\mathrm{X}$-Işını difraksiyon (XRD) analiz sonuçları incelendiğinde A1 ve Cr horizonunda birincil mineraller olan kuvars ve muskovit gibi minerallerin yanında albit ve ortoklas gibi feldspatların fazlaca 
bulunduğu görülmektedir (Çizelge 2). Söz konusu minerallerin ana materyalden kalıtsal olarak toprağa geçtiği görülmektedir.

Profil 6 alüviyal anamateryal üzerinde oluşmuş A-C horizon yapısına sahip genç topraklardır. $\mathrm{Bu}$ profilde kumlu tın toprak bünyesi ve fazla geçirgenlik görülmektedir. Söz konusu profil alüviyal toprakların genel karakteristikleri olan karışık bir mineralojik bileşime sahiptir (Çizelge 2). Nitekim Şekil 3 XRD difrogramlarında belirlenen verilere göre kuvars, feldspatlar ve mika gibi birincil minerallerin yanında kaolinit ve montmorillonit gibi sekonder yapıdaki kil mineralleri bulunmaktadır.

Profil 7, miosen yaşlı, eski kapalı göl teraslarında oluşmuştur. Kireçli ve killi çökellerden oluşan hafif eğimli yamaç bir arazide incelenen bu profilde, yüzeyde Ap horizonu vardır. Profil boyunca 2:1 tipi killerin hakim olduğu vertisol topraklardır. Kuruyken çok sert bir kıvamın ve yaz aylarında geniş çatlaklara sahip söz konusu profilin Ap ve AC horizonlarında kuvars mineralinin oldukça yüksek seviyede olduğu, bunun yanında kristobalit gibi kuvars grubu mineralleri içerdiği görülmektedir. Bunların yanında anortit, kalsit, zeolit ve montmorillonit de saptanmıştır. Zeolitin incelenen profilin kapalı göl ortamında oluşması nedeniyle, söz konusu ortamda çökeldiği, montmorillonitin ise feldspatların ve kalsitin ayrışma ürünü olarak oluştuğu düşünülmektedir. Nitekim Millot (1970); Kadir ve Karakaş (2002 ) de smektitlerin feldspatların bozunması ile oluşabildiğini bidirmektedirler. Sayın (1999), suyun hareket etmediği koşullarda sepiyolit, paligorskit ve zeolit gibi killerin çökeldiğini belirtmektedir. Araştırıcı, bu profilde olduğu gibi, kireçli ortamlarda yüksek pH, $\mathrm{Ca}$ ve $\mathrm{Mg}$ ionlarının smektitik killerin kararlı kalmasını sağladığını vurgulamaktadır.Yüzey horizonunda kalsitin bulunmaması bu mineralin yüzeyde ayrıştığının bir göstergesi sayılmalıdır. İllitin ise feldspat bozunması veya detritik yolla oluştuğu düşünülmektedir.

\section{Çalışma Alanı Toprakların Sınıflandırılması}

Çalışma alanında açılan profiller Toprak Taksonomisi (Keys to Soil Taxonomy, 2014) ve WRB toprak sınıflandırma sistemine (IUSS, 2014) göre sınıflandırılmıştır (Çizelge 3).

Çizelge 3. Çalışma alanı topraklarının Toprak Taksonomisi ve WRB sınıflandırma sistemine göre siniflandirilması

\begin{tabular}{|c|c|c|c|c|c|}
\hline \multicolumn{5}{|c|}{ Toprak Taksonomisi (Keys to Soil Taxonomy 2014) } & IUSS, 2014 \\
\hline Profil & Ordo & Alt ordo & Büyük grup & Alt grup & Referans toprak grubu \\
\hline 1 & Mollisol & Xerolls & Haploxerolls & $\begin{array}{c}\text { Lithic } \\
\text { Haploxerolls }\end{array}$ & Sceletic Phaeozems \\
\hline 2 & Alfisol & Xeralfs & Haploxeralfs & $\begin{array}{c}\text { Typic } \\
\text { Haploxeralfs }\end{array}$ & Chromic Luvisols \\
\hline 3 & Mollisol & Xerolls & Calcixerolls & Typic Calcixerolls & $\begin{array}{l}\text { Leptic Calcisols } \\
\text { (Collovic) }\end{array}$ \\
\hline 4 & İnceptisol & Xerepts & Haploxerepts & $\begin{array}{c}\text { Vertic } \\
\text { Haploxerepts }\end{array}$ & $\begin{array}{l}\text { Vertic, Fluvic } \\
\text { Cambisols }\end{array}$ \\
\hline 5 & Mollisol & Xerolls & Haploxerolls & $\begin{array}{c}\text { Lithic } \\
\text { Haploxerolls }\end{array}$ & $\begin{array}{l}\text { Leptic Phaeozems } \\
\text { (chromic) }\end{array}$ \\
\hline 6 & Entisol & Fluvent & Xerofluvents & $\begin{array}{c}\text { Typic } \\
\text { Xerofluvents }\end{array}$ & Fluvisols \\
\hline 7 & Vertisol & Xererts & Haploxererts & $\begin{array}{c}\text { Chromic } \\
\text { Haploxererts }\end{array}$ & $\begin{array}{l}\text { Haplic Vertisols } \\
\text { (Grumic) }\end{array}$ \\
\hline
\end{tabular}

Yaz aylarının oldukça sıcak ve kurak, kışların ise yağışlı ve soğuk geçtiği Çan ve Bayramiç ilçeleri Akdeniz iklim tipine yakındır. Genel olarak temmuz, ağustos ve eylül aylarında yağış görülmemesi yıllık yağış miktarının $655 \mathrm{~mm}$, yıllık ortalama toprak sıcaklığının $\left(50 \mathrm{~cm}\right.$ de) $16.9^{\circ} \mathrm{C}$ (Anonim, 1999) olması nedeniyle nem rejimi xeric ve toprak sicaklık rejimi ise thermic olarak değerlendirilmiş̧tir. Çalışma alanında Profil 1, 3 ve 5, \% 1 den fazla organik madde içermesi, sert ve çok sert kıvamda olmamaları ve renk valüsü ile kromasının düşük olması nedeniyle bir mollic epipedona sahiptirler ve bu nedenle toprak taksonomisinin mollisol ordosunda, xeric nem rejiminde oluşmaları nedeniyle de xerolls alt ordosunda yer almışlardır. Profil 1 ve $5,50 \mathrm{~cm}$ 'den daha sı̆ olmaları nedeniyle lithic haploxerolls, profil 3 ise kireçli olması nedeniyle typic calcixerolls olarak sınıflandırılmıştır Profil 2 ise xeric nem rejiminde oluşması ve argillic horizon içermesi nedeniyle typic haploxeralfs, 4 no'lu profil kambik horizon içermesi ve çatlaklara sahip olması nedeniyle vertic 
haploxerepts, 6 no'lu profil alüviyal depozitler üzerinde oluşması nedeniyle typic xerofluvents ve 7 no'lu profil ise yüksek miktarda şişen tipte kil (2:1 tipi) ve derin çatlaklar içermesi ve nemli value değerinin 4 veya daha fazla olması nedeniyle chromic haploxererts olarak sınıflandırılmıştır. WRB sinıflandırma sistemine göre 1 no'lu profil sceletic Phaozems, 5 no'lu profil leptic Phaozems, 2 no'lu profil chromic Luvisols, 3 no'lu profil leptic Calcisols, 4 no'lu profil vertic fluvic Cambisols ve 6 no'lu profil Fluvisols ve 7 no'lu profil ise haplic vertisols olarak sınıflandırılmıştır (Çizelge 3).

\section{Sonuç ve Öneriler}

Çanakkale ili Bayramiç-Çan ilçeleri arasında kalan yaklaşık 50 km'lik alanda yürütülen çalışmada, incelenen yedi adet toprak profili, morfolojik gözlemler ve laboratuar analiz sonuçları dikkate alınarak yorumlanmıştır. Horizon esasına göre alınan toprak örneklerinde, fiziksel, kimyasal ve mineralojik analizler yapılmıştır. Toprak profillerinin biri hariç (p6) diğerleri genellikle yüksek araziler üzerinde ve yerinde oluşmuş topraklardır. Profil 6 ise, dere taşkınlarının oluşturduğu genç teraslarda oluşmuş alüviyal topraklardır. Morfolojik arazi gözlemleri ve laboratuvar analizlerine bağlı olarak söz konusu profillerin yüzey ve yüzey altı tanımlama horizonlanı belirlenmiş ve araştırma toprakları uluslararası toprak sinıflandırma sistemlerine (Toprak taksonomisi ile WRB) göre sınıflandırılmıştır. Yapılan sınıflamada, araştırma alanı toprakları Toprak taksonomisinin alfisol, mollisol, inceptisol, entisol ve vertisol ordolarında yer almıştır. WRB sınıflandırma sistemine göre ise söz konusu profiller, Phaozems, Luvisols, Calcisols, Cambisols, Fluvisols ve vertisols referans gruplarında yer almışlardır. Söz konusu profillerin yapılan XRD analizlerinde kalsit, kuvars, feldspat ve mikalar en çok saptanan primer mineraller, montmorillonit en bol rastlanan kil minerali olarak belirlenmiştir. Profil 1 ve 7 'de saptanan zeolit ise söz konusu profillerin eski kapalı göl ortamlarında çökelme ile oluşmuştur. İncelenen profillerin profil gelişimi ve horizon sayısı genellikle topoğrafik koşullara bağlı olarak değiştiği belirlenmiştir.

Çalışma alanında arazi eğimine bağlı olarak değişkenlik gösteren hafif - orta derecedeki su erozyonu, toprak sığlığı ve bazı horizonlarda görülen yüzey taşlılığı en önemli sorun olarak saptanmıştır. Bölge topraklarının bazılarında yüksek kireç miktarı görülmektedir ve yüzeyden alt horizonlara inildikçe kireç miktarı artmaktadır. Bu kısımlarda önlem alınarak Yapılan analizler sonucunda bölgede organik madde içeriğinin hakim bitki örtüsünün orman ağaçlarından oluşması nedeniyle, genellikle orta veya yeterli seviyede olduğu saptanmıştır. Ancak bazı profillere (p2 ve p4) ait toprakların organik madde içeriği bakımından oldukça fakir $(\% 1.6<)$ olduğu tespit edilmiştir. $\mathrm{Bu}$ profillerde organik madde içeriğini yeterli seviyeye getirmek amacıyla organik gübreleme (ahır gübresi, yeşil gübreleme vb) uygulanabilir. Çalışma alanı genellikle engebeli arazilerden oluşmaktadır. Bazı profillerin bulunduğu alanlarda (p2 ve p3) ceviz, badem, elma kiraz gibi bitkiler yetiştirilebilmekle birlikte, diğer arazilerin (p1, p4, ve p5) tarımsal amaçlı kullanımı yerine orman arazisi olarak değerlendirmek daha doğru bir yaklaşım olacaktır. Alüviyal arazilerde oluşmuş profil 6'nın bulunduğu topraklar yöreye uygun her türlü bitki yetiştiriciliğine uygun iken, eğimli eski göl teraslarında oluşmuş profil 7'nin bulunduğu sahanın ise killi bünyeleri nedeniyle hububat ve ayçiçeği gibi tarla bitkileri tarımında kullanılması daha uygun olacaktır.

Not: Bu makale 1. yazarın Yüksek Lisans tezinden üretilmiştir.

\section{Kaynaklar}

Anonymous, 1951. Soil Survey Staff. Soil Survey Manual. United States Department of Agriculture Handbook, 18. US Goverment Printing Office Washington.

Anonim, 1999. T.C. Başbakanlık Köy Hizmetleri Genel Müdürlüğü Yayınları, Çanakkale İli Arazi Varlığı, İl Rapor No:17, ANKARA.

Anonim, 2012. Climate Data. 17 Kasım 2018, https://tr.climate-data.org/asya/tuerkiye/canakkale/can19594/\#climate-graph

Anonim, 2016. b- Mekan 360. 22 Şubat 2017, http://canakkale.mekan360.com/iys_ilcelerimiz,sehirID=17,ilceID=204,kriter39=51-ilcelerimizcanakkale-can.html?\#liste

Bouyoucos, G.J., 1951. A. Recalibration of the Hydrometer Methods for Making Mechanical Anlysis of Soil Agron. Jour. No:43.

Bozcu, M., Çalık, A., 2006. Biga Yarımadası'nın Morfotektonik Özellikleri ve Kazdağlarının Jeolojisi. Kaz Dağları 3. Ulusal Sempozyumu Bildiri Kitabı 22-24 Haziran 2006. Çanakkale. s.29-39. 
Dengiz, O., Efendiler, A., 2016. Farklı iki fizyografik ünite üzerinde oluşmuş toprakların karakteristiklerinin belirlenmesi ve dağılım haritalarının oluşturulması. TÜCAUM Uluslararası Coğrafya Semp. Intern. Geography Symp. 13-14 Ekim 2016 /13-14 October 2016, Ankara.

Dinç, U., Şenol, S., 1998. Toprak Etüd ve Haritalama. Çukurova Üniversitesi. Gen Yayınları. No:161 Ders Kitapları Yayınları. No: 50. Adana.

Ergene, A., 1963. Fırat Nehri ile Amanos Dağları Arasındaki Bölgede Teşekkül Eden Kızıl Topraklar Üzerinde Bir Araştırma (Doktora Tezi). A.Ü.Z.F. Yay. No.:2, Ankara.

Grewelling, T., Peech, M., 1960. Chemical Soil Test. Cornell Univ. Agr. Expt. Sta. Bull., No: 960.

IUSS Working Group WRB., 2015. World Reference Base for Soil Resources 2014, update 2015 International soil classification system for naming soils and creating legends for soil maps. World Soil Resources Reports No. 106. FAO, Rome.

Kadir, S., Karakaş, Z., 2002. Mineralogy, chemistry and origin of halloysite, kaolinite and smectite from Miocene ignimbrites, Konya, Turkey. Neues Jahrbuch Fur Mineralogie Abhandlungen. 177, 113-132.

Krasilnikov, P.V., Calderon Garcia, N.E., Sedov, S.N., Gomez, E., Ramos Bello, R., 2005. The relationship between pedojenik and geomorphic processes in mountainous forested area in Sierra Madre Del Sur, Mexico. Catena. 62, 14- 44.

Millot, G., 1970. Geology of clays. Translated by W.R Farrand and H. Paquet. Springer Verlag, New York, Berlin, 429p.

Mutlu, H.H., 2010. Eski Konya gölü kuvarterner terasları üzerinde oluşan toprakların jeokimyasal özellikleri ve ayrışma oranları. Yüksek lisans tezi. Selçuk Üniversitesi Fen Bilimleri Enstitisü. Konya

Pamuk, A., Ekinci, H., 2018. Çan (Çanakkale) yöresi bazı büyük toprak gruplarının (1938) özellikleri ve sınıflandırılması ÇOMÜ Zir. Fak. Derg. (COMU J. Agric. Fac.) 2018: 6 (Özel Sayı): 281-287.

Richards, L.A., 1954. Diagnosis and Improvement of Saline and Alkali Soils. United States Department of Agriculture Handbook 60:94.

Sağlam, M.T., 2008. Toprak ve Suyun Kimyasal Analiz Yöntemleri. Namık Kemal Üniversitesi Ziraat Fakültesi Yayınları. No: 2. Tekirdağ. S.154.

Sayın, M., 1999. Toprak Mineralojisi. Ç.Ü. Ziraat Fak. Gen. Yayın No:227, Ders Kitapları Yayın No.A72.Adana.

Schlichting, E., Blume, E., 1966. Bodenkundliches Practikum. Verlag Paul Parey, Hamburg und Berlin.

Soil Survey Staff, 1999. Soil Taxonomy: A Basic System of Soil Classification for Making and Interpreting Soil Surveys. USDA, NRCS Agriculture Handbook, 436, USA.

Soil Survey Staff., 2014. Keys to Soil Taxonomy. Soil Survey Staff, U.S. Department of Agriculture, Soil Conservation Service. S.372.

Soori, M., Jafari, M., Azar Nivand, H., Sharifani, F., 2006. A study on and comparison between soil nutrient statuses with a focus on $\mathrm{K}, \mathrm{P}$ and $\mathrm{N}$ in agricultural and pasture lands of Kermanshah province: A case study. Journal of Agricultural and Horticultural Research. No 71, 50-41.

Whitting, L.D., Allardice W.R., 1986. X-Ray Diffraction Techniques. In: Klute, A., Ed., Methods of Soil Analysis, Part 1: Physical and Mineralogial Methods, American Society of Agronomy, Madison, 331362.

Yılmaz, K., 1999. Harran ovası topraklarında smektit ve paligorskit oluşumu. Turkish Journal of Agriculture and Forestry 23. Ek Sayı 3, 635-642.

Yılmaz, Y., 2001. Kazdağı yakın çevresinin jeolojik özellikleri. TMMOB, Orman Mühendisleri Odası, Kazdağları 1. Ulusal Sempozyumu, 20-22 Eylül, Edremit-Balıkesir. s.15-25.

Yüksel, O., Ekinci, H., 2008. Bayramiç ilçesi arazi kaynaklarının değerlendirilmesi. Çanakkale İli Değerleri Sempozyumu. Bayramiç-Çanakkale. 